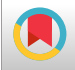

\title{
Prevalence of Fear of Childbirth and Its Associated Factors in Primigravid Women: A Cross- Sectional Study
}

\author{
Soheila Pirdadeh Beiranvand, ${ }^{1}$ Zahra Behboodi Moghadam,, ${ }^{2}$ Mahvash Salsali, ${ }^{3}$ Hamid Alavi Majd, ${ }^{4}$ \\ Mehdi Birjandi, ${ }^{5}$ and Zahra Bostani Khalesi ${ }^{6}$ \\ ${ }^{1}$ Department of Reproductive Health, School of Nursing and Midwifery, Lorestan University of Medical Sciences, Khorramabad, IR Iran \\ ${ }^{2}$ Department of Reproductive Health, School of Nursing and Midwifery, Tehran University of Medical Sciences, Tehran, IR Iran \\ ${ }^{3}$ Department of Nursing Education, School of Nursing and Midwifery, Tehran University of Medical Sciences, Tehran, IR Iran \\ ${ }^{4}$ Department of Biostatistics, School of Paramedical Sciences, Shahid Beheshti University of Medical Sciences, Tehran, IR Iran \\ ${ }^{5}$ Department of Biostatistics and Epidemiology, School of Health and Nutrition, Lorestan University of Medical Sciences, Khorramabad, IR Iran \\ ${ }^{6}$ Department of Midwifery, Faculty of Nursing and Midwifery, Guilan University of Medical Science, Rasht, IR Iran \\ "Corresponding author: Zahra Behboodi Moghadam, Associate Professor, Department of Reproductive Health, School of Nursing and Midwifery, Tehran University of Medical \\ Sciences, Tehran, IR Iran. Tel: +98-9122494201, E-mail: bahar_behboodi@yahoo.com
}

Received 2017 April 06; Revised 2017 September 19; Accepted 2017 October 08.

\begin{abstract}
Background and Objectives: Fear of childbirth is a common concern among pregnant women, which is why many women request Cesarean section. Therefore, this study aimed at determining the prevalence of fear of childbirth and its associated factors in primigravid women in Khorramabad, Lorestan province, Iran.

Methods: This cross-sectional study was conducted on 400 primigravid women (gestational age: 18 - 32 weeks), who referred to the health centers and stations of Khorramabad in 2014 for routine prenatal care. The participants were selected through multistage cluster sampling method. Childbirth attitude questionnaire (CAQ), demographic characteristics and pregnancy characteristics questionnaires, and Northouse social support questionnaire were used to collect data. The data were analyzed using chi-square test, t test, Mann-Whitney test, and multivariate logistic regression.

Results: The mean score for the fear of childbirth was 37.86 ( \pm 9.44 ), and the prevalence of fear of childbirth was $80.8 \%$ (CAQ $\geq$ 28). According to the results of multivariate logistic regression analysis, lack of sufficient income for living expenses $(P=0.020)$, not participating in childbirth preparation classes $(P=0.040)$, and preference for mode of delivery (vaginal delivery) $(\mathrm{P}<0.001)$ were predictive factors for the fear of childbirth.

Conclusions: According to the results of this study, most primigravid women had experienced the fear of childbirth. Therefore, it is required the health care providers pay special attention to the fear of childbirth during pregnancy and the factors associated with it.

Keywords: Prevalence, Fear of Childbirth, Primigravid, Cross- Sectional Study
\end{abstract}

\section{Background}

Pregnancy, childbirth, and transition to parenthood are normal physiological processes that are accompanied by important social and emotional conflicts for any woman and her family (1). Most healthy women in developed countries should be able to experience childbearing as a positive life event that has very few adverse consequences (2). Although most of women have good health in Western countries, the rate of childbirth interventions such as cesarean- section is high among them; for instance, the rate of cesarean delivery was $32.8 \%$ in the United States in 2012 (3). According to information obtained from Lorestan University of Medical Sciences, the rates of ce- sarean delivery in social security, private, and public centers were $43 \%$, 93\%, and 39\%, respectively, in Khorramabad and $44 \%$ in Lorestan province. In Iran, the rate of cesarean delivery is 3 times as high as the world average (4), and with a prevalence of $45.55 \%$, it is considered among the countries at risk for cesarean delivery (5). Furthermore, studies show that only $15 \%$ of deliveries need a cesarean- section (68).

Many studies reported the most common reason for choosing cesarean delivery by women who have not experienced childbirth is the fear of childbirth. The prevalence of fear of childbirth has been reported as 5\% to 30\% in Sweden, Switzerland, and Australia (9-14). Approximately 6\% to $10 \%$ of women experience an intense fear of labor and birth 
that is debilitating and disrupts the labor process $(9,15,16)$. According to a study conducted on primiparous women in Tehran, $74.3 \%$ of women selected cesarean- section due to fear of labor pain (17).

Fear of childbirth in nulliparous women is more intense than in multiparous women $(11,18,19)$. According to previous studies, if a pregnant woman experiences a higher fear of childbirth in the third trimester of pregnancy for whatever reason, the risk of cesarean- section increases, even if she is physically healthy. In women with tokophobia, the demand for abortion or a cesarean- section is the only way to avoid fear $(20,21)$.

According to various studies, personal and external conditions (environmental and contextual) play an important role in causing the fear of childbirth. Personal conditions reflect women's concerns about maintaining a sense of personal control. In a study, of the 100 women who suffered an intense fear of childbirth, over $65 \%$ were worried about their performance in labor and their bodies' abilities to give birth (22). These concerns were attributed to having little hope for overcoming the labor and achieving positive outcomes $(23,24)$. External conditions refer to the environment and context, where women give birth, and their interactions with health care professionals. For example, a study reported the lack of trust in the obstetric staff as the most common cause of fear of childbirth (9).

Fear of childbirth in multiparous women can be related to the previous experience of traumatic or negative delivery $(12,25-27)$. Although delivery is considered to be a natural phenomenon, women's labor experiences are not only dependent on interventions and medical complications during labor, but also are related to their traumatic and negative experiences $(28,29)$. Studies have shown that when women have pain during labor, it is highly important for them how the personnel deal with them (29-31).

Some women appear to be at greater risk for the experience of fear of childbirth compared to others. Sociodemographic characteristics such as low educational level, lack of social support, marital dissatisfaction, being young, unemployment, and having heard bad stories about pregnancy and childbirth are associated with fear of childbirth $(14,18,32-34)$. Other risk factors include the history of negative experience of delivery, operative delivery, emergency Cesarean section, violence, and sexual abuse $(11,12,35,36)$.

Women with anxiety disorders and depression are at greater risk for experiencing fear of childbirth $(14,18,34)$. Moderate to severe level of fear of childbirth is associated with some anxiety disorders such as panic and posttraumatic stress disorder (37). Some characteristics such as fear of pain and low level of pain tolerance are also known as the causes of fears of childbirth $(13,32,38)$. Some other reasons include fear of mother's death, fear of losing con- trol, or fear of expressing stupid behaviors during labor (32).

Other psychological and social factors affecting the fear of childbirth include fear of the unknown, desire for pain relief, physical and mental relaxation, mother's personality traits, genetic background that makes a person vulnerable to stress, unpleasant experience and receiving encouragement from others, concern about adverse complications for mother, inappropriate behavior of the medical staff, fear of dying and being alone, concern about the health of the baby, lack of adequate social support, being young, unemployment, and low education and income. The fear of labor pain is also a predictive factor of pain during labor that may increase the risk of emergency cesareansection and the rate of elective cesarean-section $(9,15,27$, $34,39,40)$.

The results of studies on the causes of fear of childbirth show that many women are afraid of childbirth because they have no control over the actions which they are supposed to do. This causes the physiological process of labor to be transformed into a medical problem (32).

Known physical and emotional consequences associated with fear of childbirth include voluntary infertility, pregnancy complications, increased use of analgesics during labor, increased labor interventions, increased duration of labor (41), increased elective and emergency cesarean-sections, postpartum depression, post-traumatic stress disorder (PTSD), and impaired mother-infant bonding. The role of a woman as a mother and her relationship with her infant, other children, and the husband are influenced by these consequences $(9,16,29,42,43)$.

It seems that the current situation should be investigated to design and implement appropriate intervention programs and provide strategies to promote women's health. The aim is to provide the best possible preventive strategies by determining the fear of childbirth among women and analyzing the relevant factors. Therefore, this study was conducted to determine the prevalence of fear of childbirth and its associated factors in primigravid women in Khorramabad, Lorestan province, Iran.

\section{Methods}

This cross-sectional study was conducted on 400 primigravid women who referred to 6 health centers and stations of Khorramabad from October 7 to March 16, 2014 for routine prenatal care. After the project was approved by the ethics committee of Tehran University of Medical Sciences and permission was obtained from Lorestan University of Medical Sciences, the multistage cluster sampling was performed. The sampling method was a multistage cluster method. To distribute the sample in the whole city, 
the city was divided into 3 parts: north, center, and south. The number of deliveries in each of the 3 sections was 2042, 1288 , and 1755, with and a total of 5085 births. Then, to calculate the required number of samples in each section, the sample size $(n=400)$ was divided by the total number of deliveries in the 3 sections and the result was multiplied by the population covered by each section. The required sample numbers for the north, center, and south were calculated as 161, 101, and 138, respectively. In each section, the sample share of each section was determined among 6 health centers, which were randomly selected. Pregnant women, who referred to these centers, formed our research units.

Inclusion criteria were as follow: Primigravid women (gestational age: 18 - 32 weeks), who had no medical and obstetric problems in the current pregnancy. After explaining the objectives of the study and ensuring confidentiality, and obtaining written informed consent, the participants were asked to complete the childbirth attitude questionnaire (CAQ), demographic characteristics questionnaire, pregnancy characteristics questionnaire, and Northouse social support questionnaire.

The childbirth attitude questionnaire was used to assess the fear of childbirth. This questionnaire had been revised by Lowe, and its reliability had been confirmed (Cronbach's alpha: 0.84$)(44,45)$. It includes 14 items based on the 4-point Likert scale (Not at all, too little, moderately, too much). In this questionnaire, the scores range from 14 to 56. The higher score represents higher fear. The median score, ie: 28 , was considered for the fear of childbirth. The validity and psychometric properties of this questionnaire were examined by Khorsandi (2008) in Iran, and its reliability was confirmed with a Cronbach's alpha coefficient of $0.75(4,20,46-48)$. To determine the factors associated with the fear of childbirth, Demographic characteristics, pregnancy characteristics questionnaires, and Northouse social support questionnaire were used.

Northouse social support questionnaire comprises 40 items in five 8-item domains (spouse, family members, friends, physician, and nurse) that assess the level of perceived social support from the spouse, family members, friends, the physician, and the nurses. Items are rated based on a 5-point Likert scale ranging from 1 to 5 ( $1=$ strongly disagree; 2 = disagree; $3=$ neither agree nor disagree; 4 = agree, and $5=$ strongly agree). The score of perceived social support from each of the supportive sources is calculated separately based on the total scores obtained from each source. The scores for perceived social support from each source range separately from 8 to 40 and are classified into 3 levels of low ( 8 - 18), average (19 - 29), and high $(30-40)(49,50)$. In this study, the participants only responded to questions of perceived social support from the spouse. To measure the internal consistency of the questionnaire, Cronbach's alpha was measured as 0.92 (50).

After completing the questionnaires, the data were analyzed using SPSS-21 and descriptive and analytical statistics. To determine the correlation between sociodemographic characteristics, pregnancy characteristics, perceived social support from the spouse, and the fear of childbirth, inferential tests such as chi-square test, t test, and Mann-Whitney test were used; and finally, the multivariate logistic regression analysis was used to predict the impact of each variable. Those independent variables whose p-values were less than 0.3 in the bivariate analysis were entered into the multivariate regression model. In this analysis method, those independent variables that did not have a statistically significant relationship with the dependent variable were excluded from the model, and significant variables remained in the model. Significance level was set at $\mathrm{P}<0.05$.

\section{Results}

This study was conducted on 400 primigravid women, most of whom (62.5\%) aged from 15 to 25 years. The mean age of the participants was $24.44 \pm 4.5$ years; of the participants, $85.8 \%$ were unemployed and $43.8 \%$ had high school education (Table 1 ).

Most of the women (89.5\%) received prenatal care, $28.8 \%$ had regular physical activity during pregnancy (at least 3 days a week), and 15.2\% attended childbirth preparation classes. Most of them (77.2\%) had knowledge about vaginal delivery and its stages. Most of the women (82.5\%) trusted the health personnel, 79.2\% had wanted pregnancies, and 70.8\% preferred vaginal delivery (Table 2 ). Their mean gestational age was $23.70 \pm 5.50$ weeks.

The mean score for spousal support was $30.70( \pm 4.2)$, and the participants' scores ranged from 11 to 40 .

The mean score for the fear of childbirth was 37.86 ( \pm 9.44), and the scores ranged from 14 to 56 . Fear of childbirth was observed in most of the primigravid women (80.8\% compared to $19.3 \%$ ).

The results of the independent t test revealed no statistically significant correlation between perceived social support from the spouse and fear of childbirth $(\mathrm{P}=0.3)$.

According to the results of the Mann-Whitney test, the variables of education, husband's education, and sufficient income for living expenses were not significantly correlated with the fear of childbirth. Moreover, the results of chi-square test revealed no statistically significant relationship between job, husband's job, and first source of support with fear of childbirth (Table 1 ).

According to the results of chi-square test, performing exercise during pregnancy, participating in childbirth 
Table 1. Relationship of Sociodemographic Characteristics with Fear of Childbirth in Primigravid Women ${ }^{\mathrm{a}}$

\begin{tabular}{|c|c|c|c|c|}
\hline Fear of Childbirth/Variable & No & Yes & Total & PValue \\
\hline Education & & & & 0.06 \\
\hline Illiterate & $5(6.5)$ & $7(3.2)$ & $12(3)$ & \\
\hline Elementary & $6(7.8)$ & $15(4.6)$ & $21(5.2)$ & \\
\hline Secondary & $5(6.5)$ & $25(7.7)$ & $30(7.5)$ & \\
\hline High school & $36(46.7)$ & $139(43)$ & $175(43.8)$ & \\
\hline College & $25(32.5)$ & $137(42.5)$ & $162(40.5)$ & \\
\hline Total & $77(100)$ & $223(100)$ & $400(100)$ & \\
\hline Job & & & & 0.718 \\
\hline Unemployed & $65(84.4)$ & $278(86.1)$ & $343(85.8)$ & \\
\hline Employed & $12(15.6)$ & $45(13.9)$ & $57(14.2)$ & \\
\hline Total & $77(100)$ & $323(100)$ & $400(100)$ & \\
\hline Husband's education & & & & 0.09 \\
\hline Illiterate & $2(2.6)$ & $4(1.2)$ & $6(1.5)$ & \\
\hline Elementary & $8(10.4)$ & $14(4.3)$ & $22(5.5)$ & \\
\hline Secondary & $16(20.8)$ & $41(12.7)$ & $57(14.3)$ & \\
\hline High school & $24(31.2)$ & $145(44.9)$ & $169(42.2)$ & \\
\hline College & $27(35.1)$ & $119(36.9)$ & $146(35.6)$ & \\
\hline Total & $77(100)$ & $323(100)$ & $400(100)$ & \\
\hline Husband's job & & & & 0.650 \\
\hline Unemployed & $5(6.5)$ & $29(9)$ & $34(8.5)$ & \\
\hline Employed & $72(93.6)$ & $294(91)$ & $366(91.5)$ & \\
\hline Total & $77(100)$ & $323(100)$ & $400(100)$ & \\
\hline The first source of support & $17(22.1)$ & $88(27.2)$ & $105(26.3)$ & 0.405 \\
\hline \multicolumn{5}{|l|}{ Parents } \\
\hline Spous & $56(72.7)$ & $226(70)$ & $282(70.5)$ & \\
\hline Others & $4(5.2)$ & $9(2.8)$ & $13(3.2)$ & \\
\hline Total & $77(100)$ & $323(100)$ & $400(100)$ & \\
\hline Sufficient income for living expenses & & & & 0.126 \\
\hline Not at all & $18(23.4)$ & $69(21.4)$ & $87(21.8)$ & \\
\hline Somewhat & $50(64.9)$ & $236(73.1)$ & $286(71.5)$ & \\
\hline Completely & $9(11.7)$ & $18(5.6)$ & $27(6.8)$ & \\
\hline Total & $77(100)$ & $323(100)$ & $400(100)$ & \\
\hline
\end{tabular}

${ }^{\mathrm{a}}$ Values are expressed as No. (\%).

preparation classes, and preferred mode of delivery were significantly correlated with fear of childbirth (Table 2).

Those independent variables whose P values were less than 0.3 in the bivariate analysis were entered into the multivariate regression model. In this analysis method, those independent variables that had no statistically significant correlation with the dependent variable were ex- cluded from the model, and significant variables were remained in the model.

Variables of sufficient income for living expenses, participating in childbirth preparation classes, and a preference for mode of delivery were predictors of fear of childbirth. Fear of childbirth in women, who were not satisfied with their income was 3.7 times more than those who were 
Table 2. Relationship Between the Current Pregnancy Characteristics and Fear of Childbirth in Primigravid Women ${ }^{\mathrm{a}}$

\begin{tabular}{|c|c|c|c|c|}
\hline Fear of Childbirth/Variable & No & Yes & Total & P Value \\
\hline Prenatal care & & & & 0.413 \\
\hline Yes & $67(87)$ & $291(90.1)$ & $358(89.5)$ & \\
\hline No & $10(13)$ & $32(9.9)$ & $42(10.5)$ & \\
\hline Total & $77(100)$ & $323(100)$ & $400(100)$ & \\
\hline Exercise during pregnancy & & & & 0.003 \\
\hline Yes & $33(42.9)$ & $82(25.4)$ & $115(28.8)$ & \\
\hline No & $44(57.1)$ & $241(74.6)$ & $285(71.2)$ & \\
\hline Total & $77(100)$ & $323(100)$ & $400(100)$ & \\
\hline participation in childbirth preparation classes & & & & 0.007 \\
\hline Yes & $20(26)$ & $41(12.7)$ & $61(15.2)$ & \\
\hline No & $57(74)$ & $282(87.3)$ & $339(84.8)$ & \\
\hline Total & $77(100)$ & $232(100)$ & $400(100)$ & \\
\hline Information about childbearing process & & & & 0.99 \\
\hline Yes & $60(77.9)$ & $249(77.1)$ & $309(77.2)$ & \\
\hline No & $17(22.1)$ & $74(22.9)$ & $91(22.8)$ & \\
\hline Total & $77(100)$ & $323(100)$ & $400(100)$ & \\
\hline Trust in health personnel & & & & 0.506 \\
\hline Yes & $67(87)$ & $263(81.4)$ & $330(82.5)$ & \\
\hline No & $1(1.3)$ & $7(2.2)$ & $8(2)$ & \\
\hline Somewhat & $9(11.7)$ & $53(16.4)$ & $62(15.5)$ & \\
\hline Total & $77(100)$ & $323(100)$ & $400(100)$ & \\
\hline Wanted pregnancy & & & & 0.063 \\
\hline Yes & $67(87)$ & $250(77.4)$ & $317(79.2)$ & \\
\hline No & $10(13)$ & $73(22.6)$ & $83(20.8)$ & \\
\hline Total & $77(100)$ & $323(100)$ & $400(100)$ & \\
\hline Preference for mode of delivery & & & & $<0.001$ \\
\hline Vaginal & $72(93.5)$ & $211(65.3)$ & $283(70.8)$ & \\
\hline Cesarean & $5(6.5)$ & $112(34.7)$ & $117(29.2)$ & \\
\hline Total & $77(100)$ & $323(100)$ & $400(100)$ & \\
\hline
\end{tabular}

${ }^{\mathrm{a}}$ Values are expressed as No. (\%).

completely satisfied with their income $(\mathrm{P}=0.02)$. Fear of childbirth in women who participated in childbirth preparation classes was almost twice as that of those who did not $(\mathrm{P}=0.040)$. Also, the level of fear in women, who preferred vaginal delivery was 6.6 times more than those who preferred cesarean- section $(\mathrm{P}<0.001)$ (Table 3$)$.

\section{Discussion}

Pregnancy is one of the most important events in every woman's life, and fear of childbirth is a common con- cern in primigravid women. Demographic and psychological characteristics of pregnant women and their relationship with their husbands affect their attitudes toward pregnancy and fear of childbirth and often lead to request for cesarean- section (46). In this study, of the 400 primigravid women, $80.8 \%$ had experienced fear of childbirth. The results revealed significant correlations between sufficient income for living expenses $(\mathrm{P}=0.02)$, participation in childbirth preparation classes $(\mathrm{P}=0.040)$, and preference for mode of delivery $(\mathrm{P}<0.001)$, and fear of childbirth. 
Table 3. Correlation Between Sufficient Income for Living Expenses, Participation in Childbirth Preparation Classes, and Preference for Mode of Delivery and fear of Childbirth in the Primigravid Based on Multivariate Logistic Regression Model

\begin{tabular}{|c|c|c|c|c|}
\hline Variables & B & S.E & OR $(95 \% \mathrm{CI})$ & PValue \\
\hline \multicolumn{5}{|l|}{ Sufficient income } \\
\hline Not at all & 1.307 & 0.563 & $3.696(1.227-11.138)$ & 0.020 \\
\hline Somewhat & 1.227 & 0.469 & $3.410(1.360-8.552)$ & 0.009 \\
\hline Completely (reference) & - & - & - & - \\
\hline Yes (reference) & - & - & - & \\
\hline No & 0.636 & 0.324 & $1.889(1.002-3.561)$ & \\
\hline Preference for mode of delivery & & & & $<0.001$ \\
\hline Vaginal & 1.887 & 0.481 & $6.597(2.570-16.398)$ & \\
\hline Cesarean (reference) & - & - & - & \\
\hline
\end{tabular}

In a study conducted by Negahban and Ansari (2004), to determine the correlation between fear of childbirth and the risk of emergency cesarean-section in primigravid women, it was found that $93 \%$ of women had experienced fear of childbirth to some extent (51).

Fenwick et al. (2009) conducted a study in Western Australia to determine the levels of fear of childbirth before and after delivery in pregnant women and its relationship with birth outcomes. According to the findings, 26\% of women had mild fear, $48 \%$ moderate fear, and $26 \%$ intense fear of childbirth. In general, the mean score for fear of childbirth at the 36th week of pregnancy in the nulliparous women was higher than in parous women $(\mathrm{P}<$ 0.001) (9).

Nilsson et al. (2012) conducted a study in Sweden to determine the fear of childbirth during pregnancy and 1 year after childbirth and its relationship with the experience and mode of delivery. Based on their findings, no correlation was found between fear of childbirth and sociodemographic factors (age, marital status, place of birth, education level, and smoking habits). Moreover, they found no correlation between the fear of childbirth during pregnancy and parity. However, it was reported that the fear of childbirth was higher in primiparous women 1year after delivery (12).

In the present study, no significant correlations were observed between age, job, education level of the pregnant woman, and perceived social support from the spouse, and the fear of childbirth, but significant correlations were found between sufficient income for living expenses, participation in childbirth preparation classes, and preference for mode of delivery and the fear of childbirth. These results are consistent with the findings of Akhlaghi et al. (2012), who reported no correlation between age, educa- tion level of the pregnant woman, and the fear of childbirth (46). Heimstad and Norum also reported no significant correlations between education level, age, mother's job, and the fear of childbirth $(35,52)$. However, Laursen et al. concluded that the factors affecting the fear of childbirth in primiparous women including low education level, lack of social support, being housewives, and being young are significantly associated with increased fear of childbirth (33). In the study of Akhlaghi et al. (2012), no significant correlation was observed between the income and fear of childbirth (46), which is not consistent with our study. This may be because it did not cover all strata of the society and was limited only to those who referred to public hospitals. This issue can be clarified by further investigation on private and public hospitals. A study conducted on 279 women and their husbands revealed that the anxiety associated with pregnancy and fear of childbirth are higher among women with high anxiety, tension, vulnerability, depression, and low self-esteem, who do not have marital satisfaction and social support (53). In the present study, no correlation was observed between perceived social support from the spouse and the mother's fear of childbirth, which can be due to the significant role of other factors such as personality traits of the mother and the effect of her knowledge on the fear of childbirth.

The results of this study indicated that the fear of childbirth in women, who did not participate in childbirth preparation classes was almost twice as that of those who did. This is consistent with the results of a study conducted in Turkey, which revealed a significant negative correlation between the women's proper knowledge of childbirth, and their cooperation with medical staff during childbirth, and the fear of childbirth. It means that as the women's awareness of childbirth increased, their fear of childbirth 
and their request for cesarean- section decreased (54).

Inadequate childbirth-related training during pregnancy is one of the issues that should be taken into consideration. In this study, only $15.3 \%$ of women received training, while most of them did not participate in childbirth preparation classes. Training during pregnancy is an appropriate way to reduce fear of childbirth because it gives the opportunity to pregnant women to raise their awareness of pregnancy and childbirth (26).

This study indicated that the fear of childbirth among women who preferred vaginal delivery was 6.6 times more than that of those who preferred cesarean- section. Several studies reported that women who tend to have a cesareansection fear labor pain more $(17,55-57)$. This can suggest that these mothers regard cesarean delivery as a painless childbirth and this might be the reason why they feel less fear than women who have preferred vaginal delivery.

In the study of Johanson et al. the highest percentage of agreement about the pregnant mothers' attitude toward cesarean delivery was that cesarean delivery was more convenient than vaginal delivery (58). In the study of Ryding et al. most of women have expressed fear of pain as the main reason for choosing cesarean- section (59).

Liu et al. (2013) conducted a qualitative study entitled as "Understanding Women's Preferences and Motivational Factors in Choosing Mode of Delivery" on nulliparous women in Argentina. The findings revealed that most research units preferred natural childbirth due to cultural, individual, and social factors. They considered childbirth as a natural and healthy way for passing through the stage of femininity to the maternal stage. In contrast, cesareansection was considered as a medical decision and often submission to medical staff decisions in the presence of medical indications. According to the results of this study, women's preference for choosing mode of delivery depends on cultural, individual, and social factors. Therefore, in a woman who chooses cesarean delivery, the first step is to listen to her dialogues to determine her awareness of natural childbirth and cesarean- section, her information resources as well as her thoughts about her personal abilities and capabilities, and what have occurred in previous deliveries (1). Health workers must be sensitive to the fact that the information needs of all women are not the same, and their information plays a role in deciding about the mode of delivery (60).

The results of this study indicated that most of the primigravid women feared childbirth. Given that the factors associated with fear of childbirth are different in different cultures and societies, identifying these factors can be useful for planning and providing prenatal services and helping the health personnel provide better services to pregnant women. Since fear of childbirth is one of the main reasons for the increased cesarean delivery worldwide and the rate of cesarean delivery is high in Lorestan province, holding childbirth preparation classes focusing on pregnant women with fear of childbirth can be an effective measure to reduce the fear of childbirth and reinforce vaginal delivery.

The only limitation was that the study was conducted based on questionnaires with closed-ended questions and it seems that qualitative studies or open-ended questions can more deeply examine the factors associated with fear of childbirth. Therefore, due to cultural factors affecting the fear of childbirth, qualitative research is also highly recommended.

\section{Acknowledgments}

This study has been approved by Tehran University of Medical Sciences. Hereby, I would like to thank the research deputy of Tehran University of Medical Sciences, president of Lorestan University of Medical Sciences, the personnel of health centers and stations of Khorramabad, and all the pregnant women who helped us in this study.

\section{Footnote}

Conflict of Interest: The authors declare no conflict of interest.

\section{References}

1. Bewley S, Cockburn J. Responding to fear of childbirth. Lancet. 2002;359(9324):2128-9. doi: 10.1016/S0140-6736(02)09113-4. [PubMed: 12090975].

2. Geissbuehler V, Eberhard J. Fear of childbirth during pregnancy: A study of more than 8000 pregnant women. J Psychosomat Obstetr Gynecol. 2009;23(4):229-35. doi: 10.3109/01674820209074677.

3. Hamilton BE, Martin JA, Ventura SJ. Births: preliminary data for 2012. Natl Vital Stat Rep. 2013;62(3):1-20.

4. Ghooshchian S, Dehghani M, Khorsandi M, Farzad V. The role of fear of pain and related psychological variables in prediction of cesarean labor. Arak Uni Med Sci J. 2011;14(56):45-54.

5. Rashidian A, KhosraviA AM, Beheshtian M, Khabiri R, Karimi A. IR of Iran Multiple Indicator Demographic and Health Survey. Deputy Health Ministry Health Med Educ. 2010.

6. Badakhsh MH, Seifoddin M, Khodakarami N, Gholami R, Moghimi S. Rise in cesarean section rate over a 30-year period in a public hospital in Tehran, Iran. Arch Iran Med. 2012;15(1):4-7. [PubMed: 22208435].

7. Katikireddi SV, Gorman DR, Leyland AH. A comparison of trends in caesarean section rates in former communist (transition) countries and other European countries. EurJPublic Health. 2013;23(3):381-3. doi: 10.1093/eurpub/cks165. [PubMed: 23204216].

8. Wang CP, Tan WC, Kanagalingam D, Tan HK. Why we do caesars: a comparison of the trends in caesarean section delivery over a decade. Ann Acad Med Singapore. 2013;42(8):408-12. [PubMed: 24045377]. 
9. Fenwick J, Gamble J, Nathan E, Bayes S, Hauck Y. Pre- and postpartum levels of childbirth fear and the relationship to birth outcomes in a cohort of Australian women. J Clin Nurs. 2009;18(5):667-77. doi: 10.1111/j.1365-2702.2008.02568.x. [PubMed:19239535].

10. Haines H, Pallant JF, Karlstrom A, Hildingsson I. Cross-cultural comparison of levels of childbirth-related fear in an Australian and Swedish sample. Midwifery. 2011;27(4):560-7. doi: 10.1016/j.midw.2010.05.004. [PubMed: 20598787].

11. Nieminen K, Stephansson O, Ryding EL. Women's fear of childbirth and preference for cesarean section-a cross-sectional study at various stages of pregnancy in Sweden. Acta Obstet Gynecol Scand. 2009;88(7):807-13. doi: 10.1080/00016340902998436. [PubMed: 19488882].

12. Nilsson C, Lundgren I, Karlstrom A, Hildingsson I. Self reported fear of childbirth and its association with women's birth experience and mode of delivery: a longitudinal population-based study. Women Birth. 2012;25(3):114-21. doi: 10.1016/j.wombi.2011.06.001. [PubMed: 21764400].

13. Stoll K, Edmonds JK, Hall WA. Fear of Childbirth and Preference for Cesarean Delivery Among Young American Women Before Childbirth: A Survey Study. Birth. 2015;42(3):270-6. doi: 10.1111/birt.12178. [PubMed: 26104997].

14. Storksen HT, Eberhard-Gran M, Garthus-Niegel S, Eskild A. Fear of childbirth; the relation to anxiety and depression. Acta Obstet Gynecol Scand. 2012;91(2):237-42. doi:10.1111/j.1600-0412.2011.01323.x. [PubMed: 22085403].

15. Ternstrom E, Hildingsson I, Haines H, Rubertsson C. Higher prevalence of childbirth related fear in foreign born pregnant women-findings from a community sample in Sweden. Midwifery. 2015;31(4):445-50. doi: 10.1016/j.midw.2014.11.011. [PubMed: 25529841].

16. Toohill J, Fenwick J, Gamble J, Creedy DK. Prevalence of childbirth fear in an Australian sample of pregnant women. BMC Pregnancy Childbirth. 2014;14:275. doi: 10.1186/1471-2393-14-275. [PubMed: 25123448].

17. Mohammadi T, Kiani AA, Heydari M. The survey on tendencies of primiparous women for selecting the mode of delivery. ; 2009.

18. Hall WA, Hauck YL, Carty EM, Hutton EK, Fenwick J, Stoll K. Childbirth fear, anxiety, fatigue, and sleep deprivation in pregnant women. J Obstet Gynecol Neonatal Nurs. 2009;38(5):567-76. doi: 10.1111/j.15526909.2009.01054.x. [PubMed: 19883478].

19. Zar M, Wijma K, Wijma B. Pre-and postpartum fear of childbirth in nulliparous and parous women. Scandinavian J Behav Ther. 2001;30(2):75-84

20. Alipour Z, Lamyian M, Hajizadeh E, Vafaei MA. The association between antenatal anxiety and fear of childbirth in nulliparous women: a prospective study. Iran J Nurs Midwifery Res. 2011;16(2):169-73. [PubMed: 22224102].

21. Rouhe H, Salmela-Aro K, Halmesmaki E, Saisto T. Fear of childbirth according to parity, gestational age, and obstetric history. BJOG. 2009;116(1):67-73. doi: 10.1111/j.1471-0528.2008.02002.x. [PubMed: 19055652].

22. Sjogren B. Childbirth: expectations, choices, and trends. Lancet. 2000;356 Suppl:s12. [PubMed: 11191467].

23. Eriksson C, Westman G, Hamberg K. Content of childbirthrelated fear in Swedish women and men-analysis of an openended question. J Midwifery Womens Health. 2006;51(2):112-8. doi: 10.1016/j.jmwh.2005.08.010. [PubMed: 16504908].

24. Soet JE, Brack GA, Dilorio C. Prevalence and predictors of women's experience of psychological trauma during childbirth. Birth. 2003;30(1):36-46. [PubMed: 12581038].

25. Hofberg K, Ward MR. Fear of pregnancy and childbirth. Postgrad Med J. 2003;79(935):505-10. [PubMed: 13679545] quiz 508-10.

26. Melender HL. Fears and coping strategies associated with pregnancy and childbirth in Finland.J Midwifery Womens Health. 2002;47(4):25663. [PubMed: 12138933].

27. Nilsson C, Bondas T, Lundgren I. Previous birth experience in women with intense fear of childbirth. J Obstet Gynecol Neona- tal Nurs. 2010;39(3):298-309. doi: 10.1111/j.1552-6909.2010.01139.x. [PubMed: 20576072].

28. Beck CT. Birth trauma: in the eye of the beholder. Nurs Res. 2004;53(1):28-35. [PubMed: 14726774].

29. Nilsson C, Robertson E, Lundgren I. An Effort to Make All the Pieces Come Together: Women's Long-Term Perspectives on Their Experiences of Intense Fear of Childbirth. Int J Childbirth. 2012;2(4):255-68 doi: 10.1891/2156-5287.2.4.255.

30. Hodnett ED, Gates S, Hofmeyr GJ, Sakala C, Weston J. Continuous support for women during childbirth. Cochrane Database Syst Rev. 2011(2):CD003766. doi: 10.1002/14651858.CD003766.pub3. [PubMed: 21328263].

31. Larkin P, Begley CM, Devane D. Women's experiences of labour and birth: an evolutionary concept analysis. Midwifery. 2009;25(2):e4959. doi: 10.1016/j.midw.2007.07.010. [PubMed: 17996342].

32. Fisher C, Hauck Y, Fenwick J. How social context impacts on women's fears of childbirth: a Western Australian example. Soc Sci Med. 2006;63(1):64-75. doi:10.1016/j.socscimed.2005.11.065. [PubMed: 16476516].

33. Laursen M, Hedegaard M, Johansen C, Danish National Birth C. Fear of childbirth: predictors and temporal changes among nulliparous women in the Danish National Birth Cohort. BJOG. 2008;115(3):35460. doi: 10.1111/j.1471-0528.2007.01583.x. [PubMed: 18190372].

34. Ryding EL, Wirfelt E, Wangborg IB, Sjogren B, Edman G. Personality and fear of childbirth. Acta Obstet Gynecol Scand. 2007;86(7):814-20. doi:10.1080/00016340701415079. [PubMed: 17611826].

35. Heimstad R, Dahloe R, Laache I, Skogvoll E, Schei B. Fear of childbirth and history of abuse: implications for pregnancy and delivery. Acta Obstet Gynecol Scand. 2006;85(4):435-40. doi: 10.1080/00016340500432507. [PubMed:16612705].

36. Lukasse M, Vangen S, Oian P, Kumle M, Ryding EL, Schei B, et al. Childhood abuse and fear of childbirth-a population-based study. Birth. 2010;37(4):267-74. doi: 10.1111/j.1523-536X.2010.00420.x. [PubMed: 21083717].

37. Zar M, Wijma K, Wijma B. Relations between anxiety disorders and fear of childbirth during late pregnancy. Clin Psychol Psychother. 2002;9(2):122-30. doi: 10.1002/cpp.305.

38. Sercekus P, Okumus H. Fears associated with childbirth among nulliparous women in Turkey. Midwifery. 2009;25(2):155-62. doi 10.1016/j.midw.2007.02.005. [PubMed: 17600599].

39. Laursen M, Johansen C, Hedegaard M. Fear of childbirth and risk for birth complications in nulliparous women in the Danish National Birth Cohort. BJOG. 2009;116(10):1350-5. doi: 10.1111/j.14710528.2009.02250.x. [PubMed: 19538412].

40. Nilsson C, Lundgren I. Women's lived experience of fear of childbirth. Midwifery. 2009;25(2):e1-9. doi: 10.1016/j.midw.2007.01.017. [PubMed: 17512645].

41. Adams SS, Eberhard-Gran M, Eskild A. Fear of childbirth and duration of labour: a study of 2206 women with intended vaginal delivery. BJOG. 2012;119(10):1238-46. doi: 10.1111/j.1471-0528.2012.03433.x. [PubMed: 22734617].

42. Green JM, Baston HA. Have women become more willing to accept obstetric interventions and does this relate to mode of birth? Data from a prospective study. Birth. 2007;34(1):6-13. doi: 10.1111/j.1523536X.2006.00140.x. [PubMed: 17324172].

43. Waldenstrom U, Hildingsson I, Ryding EL. Antenatal fear of childbirth and its association with subsequent caesarean section and experience of childbirth. BJOG. 2006;113(6):638-46. doi: 10.1111/j.14710528.2006.00950.x. [PubMed: 16709206].

44. Lowe NK. Self-efficacy for labor and childbirth fears in nulliparous pregnant women. J Psychosomat Obstetr Gynecol. 2009;21(4):219-24. doi: $10.3109 / 01674820009085591$

45. Tanglakmankhong K, Perrin NA, Lowe NK. Childbirth Self-Efficacy Inventory and Childbirth Attitudes Questionnaire: psychometric properties of Thai language versions. J Adv Nurs. 2011;67(1):193-203. doi: 
10.1111/j.1365-2648.2010.05479.x. [PubMed: 21158905].

46. Akhlaghi F, Mokhber N, Shakeri MT, Shamsa F. Relation Between Depression, Anxiety, Self-Esteem, Marital Satisfaction. ; 2012.

47. ChoobMasjedi SG, Hasani J, Khorsandi M, Ghobadzadeh M. Cognitive factors related to childbirth and their effect on women's delivery preference: a comparison between a private and public hospital in Tehran. Eastern Mediterranean Health J. 2012;18(11):1127.

48. Khorsandi M, Ghofranipour FA, Heydarnia A, FaghihZadeh S, Vafaei MA, Rousta F, et al. The effect of childbirth preparation classes on childbirth fear and normal delivery among primiparous women. Arak Univ Med Sci J. 2008;11(3):29-36.

49. Ghodusi M, Heidari M, Hoseini E. Correlation Between Body Esteem and Perceived Social Support in Patients With Multiple Sclerosis (MS) Referred to the MS Society in Tehran. Sci J Ilam Univ Med Sci. 2013;21(6):215-23.

50. Heydari S, Salahshourian-fard A, Rafii F, Hoseini F. Correlation of perceived social support from different supportive sources and the size of social network with quality of life in cancer patients. Iran J Nurs. 2009;22(61):8-18.

51. Negahban T, Ansari A. Does fear of childbirth predict emergency cesarean section in primiparous women? J Hayat. 2009;14(4):73-81.

52. Nerum H, Halvorsen L, Sorlie T, Oian P. Maternal request for cesarean section due to fear of birth: can it be changed through crisis-oriented counseling? Birth. 2006;33(3):221-8. doi: 10.1111/j.1523536X.2006.00107.x. [PubMed: 16948722].
53. Saisto T, Salmela-Aro K, Nurmi JE, Halmesmaki E. Psychosocial characteristics of women and their partners fearing vaginal childbirth. BJOG. 2001;108(5):492-8. [PubMed:11368135].

54. Wadhwa PD, Dunkel-Schetter C, Chicz-DeMet A, Porto M, Sandman CA. Prenatal psychosocial factors and the neuroendocrine axis in human pregnancy. Psychosom Med. 1996;58(5):432-46. [PubMed: 8902895].

55. Akarsu RH, Mucuk S. Turkish women's opinions about cesarean delivery. Pak J Med Sci. 2014;30(6):1308-13. doi: 10.12669/pjms.306.5748. [PubMed: 25674129].

56. Azami-Aghdash S, Ghojazadeh M, Dehdilani N, Mohammadi M, Asl Amin Abad R. Prevalence and Causes of Cesarean Section in Iran: Systematic Review and Meta-Analysis. Iran JPublic Health. 2014;43(5):54555. [PubMed: 26060756].

57. Torloni MR, Betran AP, Montilla P, Scolaro E, Seuc A, Mazzoni A, et al. Do Italian women prefer cesarean section? Results from a survey on mode of delivery preferences. BMC Pregnancy Childbirth. 2013;13:78. doi: 10.1186/1471-2393-13-78. [PubMed: 23530472].

58. Johanson RB, El-Timini S, Rigby C, Young P, Jones P. Caesarean section by choice could fulfil the inverse care law. Eur J Obstetr Gynecol Reprod Biol. 2001;97(1):20-2. doi: 10.1016/s0301-2115(01)00424-9.

59. Ryding EL. Investigation of 33 women who demanded a cesarean section for personal reasons. Acta Obstet Gynecol Scand. 1993;72(4):280-5. [PubMed: 8389515].

60. Shaw C. External assessment of health care. BMJ. 2001;322(7290):8514. [PubMed: 11290644]. 